\title{
Genetic Determination of Methylenomycin Synthesis by the SCP1 Plasmid of Streptomyces coelicolor A3(2)
}

\author{
By R. KIRBY* AND D. A. HOPWOOD \\ John Innes Institute, Colney Lane, Norwich $\mathrm{NR}_{4}{ }_{7} \mathrm{UH}$
}

(Received 8 July 1976; revised 27 August 1976)

\begin{abstract}
SUMMARY
Evidence is presented that genes determining the pathway of methylenomycin A synthesis are carried on the SCPI plasmid. All I 6 mutations $(m m y)$ leading to lack of antibiotic synthesis were SCPI-linked. Phenotypic classification, by co-synthesis and other criteria, suggested that they fell into at least five classes. When the wild-type SCPI plasmid was transferred to Streptomyces lividans or Streptomyces parvulus, material that was chromatographically and biologically indistinguishable from methylenomycin A was produced. Recombination between some pairs of mmy mutations was detected. In crosses of mmy mutants of NF (integrated SCPI donor) strains with $\mathrm{SCPI}^{-}$, a very high frequency of chromosomal recombination occurred; thus methylenomycin production appears not to be an important cause of the ultra-fertility normally associated with $\mathrm{NF} \times \mathrm{SCPI}^{-}$crosses.
\end{abstract}

\section{INTRODUCTION}

Vivian (I97I) discovered that the SCPI plasmid of Streptomyces coelicolor A3(2) controls the synthesis of a substance which inhibits $\mathrm{SCPI}^{-}$strains and that the plasmid also confers resistance to this material. It was found to be an antibiotic (Kirby, Wright \& Hopwood, I975) and was later identified (Wright \& Hopwood, 1976a) as methylenomycin A, a compound characterized in another streptomycete (Haneishi et al., 1974).

Kirby et al. (1975) reported the isolation of plasmid-linked mutations abolishing antibiotic production. We here describe in detail the isolation and properties of the mutants. These results, and other evidence, suggest that biosynthetic genes for the whole of the pathway leading uniquely to methylenomycin A may be carried on the SCPI plasmid.

\section{METHODS}

Media, strains and standard genetical procedures. Minimal (MM) and complete (CM) media and supplementation of MM with growth requirements or streptomycin were as described previously (Hopwood, 1967); nutrient agar (NA) was Difco Bacto-nutrient agar. Methylenomycin A ( $85 \%$ pure), kindly supplied by Dr M. Arai, Sankyo Co. Ltd, Tokyo, Japan, was added to CM at a concentration of $200 \mu \mathrm{g} \mathrm{ml}^{-1}$. Derivatives of three Streptomyces spp. (Table I) were used: S. coelicolor A3(2), S. lividans 66 (our strain 1326), described by Lomovskaya et al. (1972) and kindly supplied by Dr N. D. Lomovskaya, and S. parvulus ATCCI2434 (our strain 2266), kindly supplied by Dr H. Prauser. Eubacterial indicator strains were as listed by Wright \& Hopwood (1976a). Standard cultural and crossing procedures were those described by Hopwood (1967) and Hopwood et al. (1973). Streptomyces cultures were incubated at $30^{\circ} \mathrm{C}$, Erwinia carotovora at $27^{\circ} \mathrm{C}$, and Bacillus cereus at $36{ }^{\circ} \mathrm{C}$.

\footnotetext{
* Present address: Department of Bacteriology, University of Bristol, University Walk, Bristol BS8 ITD. I6 
Table I. Streptomyces strains

\begin{tabular}{|c|c|c|}
\hline Strain & Markers & Plasmid status \\
\hline $\begin{array}{l}S . \text { coelicolor A3(2) } \\
104 \\
417 \\
\text { I190 } \\
\text { I546 } \\
1953 \\
1956 \\
\text { I984 } \\
2455 \\
\text { A200 } \\
\text { A303 } \\
\text { A700 }\end{array}$ & 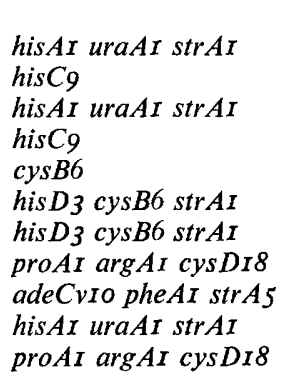 & $\begin{array}{l}\mathrm{SCPI}^{+} \\
\mathrm{SCPI}^{+} \\
\mathrm{SCPI}^{-} \\
\text {SCPI-orange } \\
\mathrm{SCPI}^{-} \\
\mathrm{SCPI}^{-} \\
\mathrm{SCPI}^{\prime} \text {-cys } \mathrm{B}^{+} \\
\mathrm{SCPI}^{-} \text {orange } \\
\mathrm{SCPI}^{-} \\
\mathrm{NF} \\
\mathrm{SCPI}^{-}\end{array}$ \\
\hline $\begin{array}{l}\text { S. lividans } 66 \\
\text { 1326 } \\
\text { 1671 }\end{array}$ & $\begin{array}{l}\text { Wild-type } \\
\text { Wild-type }\end{array}$ & $\begin{array}{l}\mathrm{SCPI}^{-} \\
\mathrm{SCPI}^{+}\end{array}$ \\
\hline $\begin{array}{l}\text { S. parvulus ATCCI } 2434 \\
2266 \\
2283 \\
2296 \\
2297\end{array}$ & $\begin{array}{l}\text { Wild-type } \\
\text { str-I } \\
\text { str-I } \\
\text { cysBI }\end{array}$ & $\begin{array}{l}\mathrm{SCPI}^{-} \\
\mathrm{SCPI}^{-} \\
\mathrm{SCPI}^{+} \\
\mathrm{SCPI}^{-}\end{array}$ \\
\hline
\end{tabular}

Mutagenesis and mutant isolation. Mutagenesis by the following agents was by standard procedures: $N$-methyl- $N$-nitro- $N$-nitrosoguanidine (NTG) (Delić, Hopwood \& Friend, I970), 8-methoxypsoralen (MOP) in the presence of $364 \mathrm{~nm}$ light (Townsend, Wright \& Hopwood, I97I) and $254 \mathrm{~nm}$ ultraviolet light (u.v.) (Harold \& Hopwood, I970).

Various strains were used as parents for the isolation of antibiotic non-producing ( $m m y)$ mutants. An SCPI ${ }^{+}$strain had the disadvantage that plasmid loss occurred more frequently than mutation (Vivian \& Hopwood, 1970), so that the majority of $\mathrm{Mmy}^{-}$derivatives of $\mathrm{SCP}_{1}{ }^{+}$were $\mathrm{SCPI}^{-}$strains. Use of an NF (integrated SCPI) strain avoided this difficulty, since $\mathrm{SCPI}^{-}$derivatives of $\mathrm{NF}$ are very rare (Vivian \& Hopwood, I970), but subsequent study of the mutations were handicapped by the difficulty of establishing their plasmidlinkage unambiguously. When $\mathrm{SCPI}^{\prime}$ plasmids were isolated (Hopwood \& Wright, $1973 b$ ), a heterozygous strain (1984) carrying $\mathrm{SCPI}^{\prime}-c y s B^{+}$, with $c y s B 6$ on the chromosome, was used exclusively for mutant isolation; plating on MM lacking cystine ensured retention of the plasmid by all except a small minority of the colonies, since integration of $\operatorname{cys}^{+}$into the chromosome followed by plasmid loss is rare (Hopwood \& Wright, 1976b). Mutants of this plasmid could be selected into further $\mathrm{A} 3(2)$ derivatives carrying $c y s B 6$, or into $c y s B$ mutants of $S$. lividans or $S$. parvulus.

Mutagenized spore suspensions were plated on supplemented MM to yield 60 to 90 colonies per plate; these were replica-plated to CM spread with dense spore suspensions of $\mathrm{SCPI}^{-}$strain I I90. After 3 to 4 days the replicas were examined for the presence of colonies that failed to inhibit growth and pigmentation (due to the pigmented antibiotic actinorhodin: Wright \& Hopwood, I976b) of the indicator strain. Presumptive mutants were re-tested for the $\mathrm{Mmy}^{-}$phenotype.

Resistance or sensitivity to methylenomycin was tested by inoculating $\mathrm{SCPI}^{+}$strain 104 at right angles to streaks of each mmy mutant on CM; inhibition of sensitive mutants was apparent after incubation for 3 to 4 days.

To test if the $\mathrm{Mmy}^{-}$phenotypes of the mutants were due exclusively to changes in the 
plasmid, each putative mutant plasmid was transferred to a new genetic background; $m m y$ derivatives of 104,1984 and A303 were transferred to 1956, I953 and A700 respectively.

Chromatography and detection of methylenomycin and its possible precursors. Cultures were grown, extracts were prepared and analysed by thin-layer chromatography in solvent 2, and u.v.-absorbing materials were detected by the methods described by Wright \& Hopwood $(1976 a)$.

Measurement of plasmid 'instability', apparent transfer frequency and 'entry disadvantage'. Plasmid loss ('instability') of derivatives of SCPI'-cysB $B^{+}$was measured by plating a slant culture derived from a single colony on non-selective medium and estimating the proportion of Cys- colonies by replica-plating to medium lacking cystine. Transfer frequencies of such mutants were measured by crossing with strain 1953, plating the crosses on MM containing cystine and estimating the proportion of $\mathrm{Cys}^{+}$colonies by replica-plating to medium lacking cystine. Transfer frequencies of the $\mathrm{SCP}_{1}+$ mutant (R27), SCP1-orange and the NF mutants (RII and R33) were measured by crossing non-selectively with $\mathrm{SCPI}^{-}$strains and classifying samples of the genotype corresponding to the $\mathrm{SCPI}^{-}$parent for methylenomycin resistance. 'Entry disadvantage' of the mutant plasmids was defined and measured as described by Kirby (1976).

Tests of reversion on transfer, and recombination, of mmy mutations. For reversion tests, a strain carrying each $m m y$ mutation of $\mathrm{SCPI}-c y s B^{+}$was crossed with strain 1953 (cysB6 $\mathrm{SCPI}^{-}$) and $\mathrm{Cys}^{+}$progeny were selected on $\mathrm{MM}$; his $D_{3}$ served as a counterselected donor marker. The resulting colonies were tested for antibiotic production by replica-plating to lawns of strain I I90. For recombination tests, triparental crosses of pairs of mmy mutations with strain $\mathbf{1} 953$ were analysed in the same way.

\section{RESULTS}

\section{Isolation and general characteristics of mmy mutants}

Table 2 summarizes some of the properties of the $m m y$ mutations. Each plasmid was transferred to a new genetic background (see Methods) and the properties recorded in Table 2 are those of the new recipient. No important difference was found between an original and a derived strain. The frequencies of mutations were $9 / 21400(0.04 \%)$ for u.v. mutagenesis and 6/19000 $(0.03 \%)$ for MOP. In one experiment with NTG no mutants occurred among 800 colonies.

Severa! mutants differed from the parent in other characters besides antibiotic production. These were: frequency of plasmid loss ('instability'), frequency of apparent plasmid transfer to an $\mathrm{SCPI}^{-}$strain, 'entry disadvantage', and sensitivity to antibiotic produced by an $\mathrm{SCPI}^{+}$strain.

There was a tendency (Table 2) for instability and transfer proficiency of the $\mathrm{SCPI}^{\prime}$-cys $B^{+}$ mutants to be inversely correlated, mutants showing instability of $10 \%$ or more being significantly impaired in apparent plasmid transfer; this is not unexpected since a high instability would have been likely to reduce apparent transfer by causing plasmid loss from newly infected recipients.

The term 'entry disadvantage' was used by Kirby (1976) to describe the failure of SCPI or marked derivatives of it to recombine freely with chromosomal genotypes in crosses. It is measured in crosses between strains of different chromosomal genotype, each carrying a different SCPI derivative. The 'entry disadvantage' of the plasmid, as defined, rises in proportion to an increase in the plasmid's ability to remain in association with its original chromosomal genotype and to prevent replacement by another plasmid within the cross. 


\section{Table 2. Properties of mmy mutants}

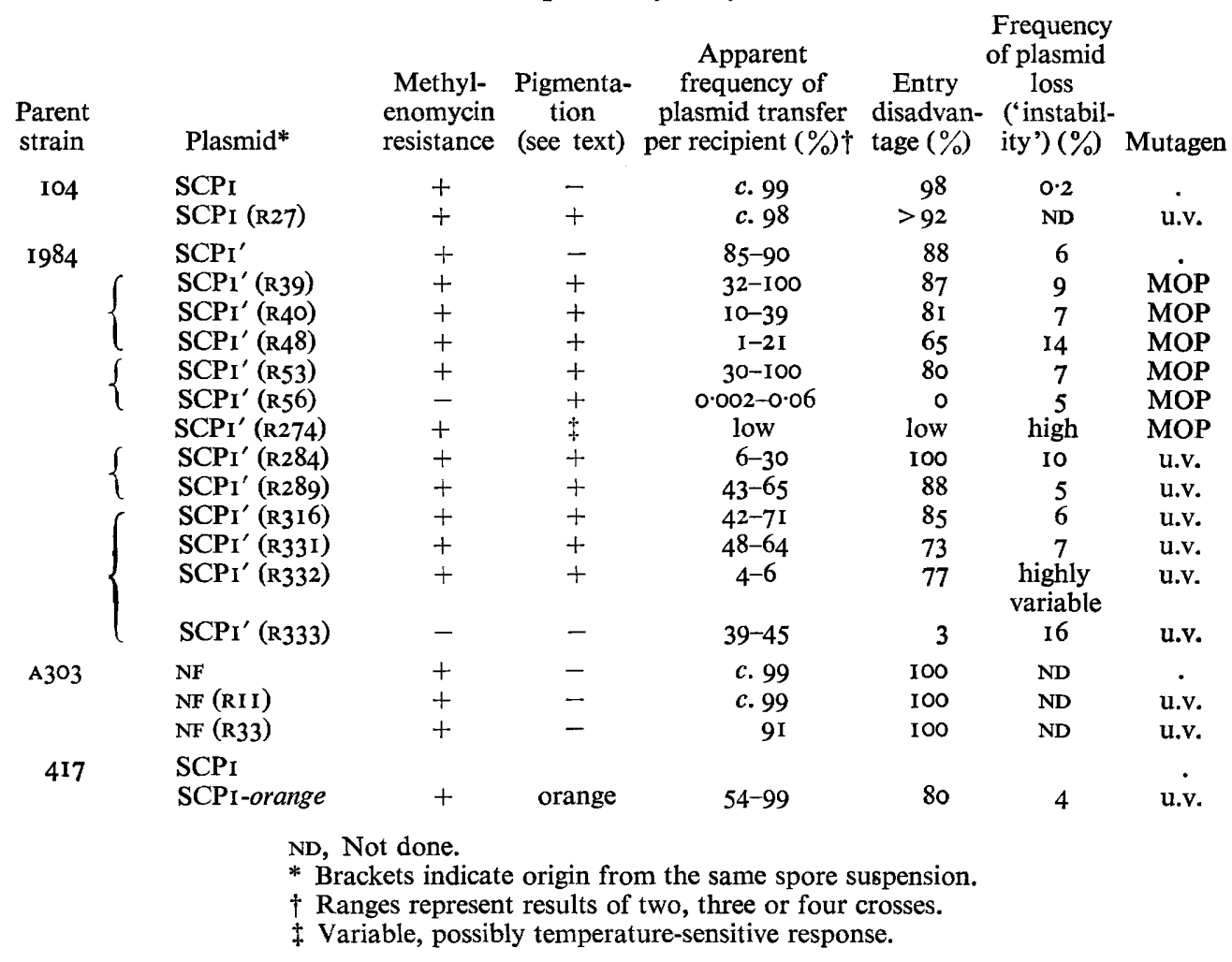

Thus NF has an 'entry disadvantage' of $100 \%$. Operational difficulties associated with the mycelial nature of streptomycetes prevented an attempt to partition this effect between phenomena that might be analogous to 'entry exclusion' and 'incompatibility' in enteric bacteria. For most of the SCPI'-cys $B^{+}$mutants, 'entry disadvantage' did not differ significantly from its value for the parent $\mathrm{SCPr}^{\prime}-$ cys $^{+}{ }^{+}$plasmid (Table 2). Exceptions were R274, whose low 'entry disadvantage' may have been explicable by its high instability, and R56 and R333 which showed very low 'entry disadvantage' but, particularly for R56, no correspondingly high instability.

Most of the mutants were resistant to antibiotic produced by the I04 tester strain, but two (R56 and R333) were apparently no more resistant than typical $\mathrm{SCPI}^{-}$strains. Four other mutants (R48, R284, R3I6 and R332) showed a partial sensitivity, but it was uncertain whether only pigmentation was affected or whether there was also a partial inhibition of growth.

The SCPI-orange mutation. Strain I546 was selected after u.v. treatment from strain 4I7 (hisC9 $\mathrm{SCPI}^{+}$) for its enhanced capacity to donate $p h e A^{+}$to an $\mathrm{SCPI}^{-}$culture (D. A. Hopwood \& H. M. Wright, unpublished results). The strain was found to be $\mathrm{Mmy}^{-}$and to produce a diffusible orange pigment on $\mathrm{CM}$, but to a negligible extent on supplemented MM. Under conditions of good production of this pigment on CM, little or no actinorhodin was formed; however, actinorhodin production on $\mathrm{CM}$ was regained on plasmid loss and was shown on MM even in the presence of the plasmid. The mutant phenotype was expressed on 


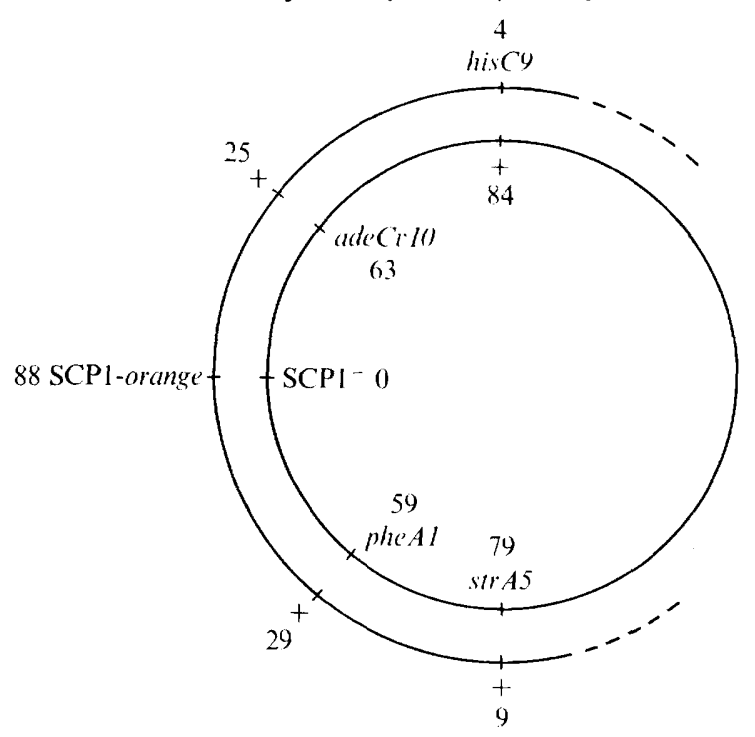

Fig. I. Interpretation of a cross between strains I 546 (hisC9 SCPI-orange: outer circle) and A200 (adeCvio pheAI strA5 $\mathrm{SCPI}^{-}$: inner circle). Figures are allele frequencies amongst total nonparental progeny. The frequencies of individual recombinant genotypes are in Table 3 .

Table 3. Non-selective analysis of a cross between strains 1546 (hisC9 SCPI-orange) and $\mathrm{A} 200$ (adeCvio pheAI strA5 $\mathrm{SCP}^{-}$)

\begin{tabular}{|c|c|c|c|c|}
\hline \multicolumn{2}{|c|}{ Genotype } & \multirow[b]{2}{*}{ No. } & \multirow[b]{2}{*}{ Description } & \multirow{2}{*}{$\begin{array}{c}\text { Percentage } \\
\text { of total } \\
\text { progeny }\end{array}$} \\
\hline Chromosomal markers & Plasmid & & & \\
\hline his & SCPI-orange & 38 & Donor parental & 22 \\
\hline ade phe str & $\mathrm{SCPI}^{-}$ & 48 & Recipient parental & 28 \\
\hline ade phe str & SCPI-orange & 56 & $\begin{array}{l}\text { Non-parental for } \\
\text { plasmid }\end{array}$ & 32 \\
\hline str & SCPI-orange & II) & & \\
\hline+ & SCPI-orange & 9 & & \\
\hline ade str & SCPI-orange & 6 & Non-parental for & 18 \\
\hline his str & SCPI-orange & 3 & markers & \\
\hline phe str & SCPI-orange & 2 & & \\
\hline his ade phe str & SCPI-orange & 1) & & \\
\hline
\end{tabular}

transfer of the plasmid to various $\mathrm{SCPI}^{-}$strains, indicating plasmid-linkage, and the plasmid was called SCPI-orange.

The donor properties of strains carrying SCPI-orange in crosses with $\mathrm{SCPI}^{-}$strains were analysed non-selectively. The frequency of recombination was much higher than in $\mathrm{SCPI}^{+x}$ $\mathrm{SCPI}^{-}$crosses, in which recombinants rarely represent more than $\mathrm{IO}^{-4}$ of the total progeny of a mixed culture (Vivian \& Hopwood, 1970; Hopwood et al., 1973), but the frequency and pattern of marker donation showed some change during the course of these studies. An early cross (Table 3; Fig. I) had a high frequency of chromosomal recombinants $(\mathrm{I} 8 \%)$ and a clear bidirectional gradient of allele ratios resembling that in $\mathrm{NF} \times \mathrm{SCPI}^{-}$crosses, but the proportion of total non-parental progeny was only some $50 \%$ instead of almost $100 \%$ characteristic of $\mathrm{NF} \times \mathrm{SCPI}^{-}$crosses (Hopwood et al., 1973). Since SCPI-orange was demonstrably unstable (Table 2 ), it was presumably autonomous, and so donation of chromosomal markers must have occurred through a transient rather than a permanent association of SCPI-orange with the chromosome, as in the unstable unidirectional donors described by Vivian \& Hopwood (1973). In later SCPI-orange $\times \mathrm{SCPI}^{-}$crosses the frequencies of 
chromosomal recombinants were lower (I to $5 \%$ ) and the gradients of allele ratios among recombinants were less marked. If the event that gave rise to the SCPI-orange plasmid was an addition (or substitution) of chromosomal DNA to SCPI, subsequent changes may have involved a loss of part of this DNA.

\section{Phenotypes of S. lividans and S. parvulus carrying SCPI and its derivatives}

In studies of inter-specific transfer of SCPI (Hopwood \& Wright, I973 $a, b$; 1976a; unpublished results), $S$. lividans 66 and $S$. parvulus ATCC1 2434 have been used extensively. Their $\mathrm{SCPI}^{+}$derivatives were previously shown to inhibit the growth of $\mathrm{SCPI}^{-}$but not $\mathrm{SCPI}^{+}$strains of $S$. coelicolor. We analysed extracts of liquid cultures of $\mathrm{SCPI}^{-}$and $\mathrm{SCPI}^{+}$ strains of both species (1326, I67I, 2283, 2296) chromatographically and found the same pattern of u.v.-absorbing spots as in S. coelicolor (Wright \& Hopwood, 1976a): spot A alone in $\mathrm{SCPI}^{-}$strains, and spots $\mathrm{A}, \mathrm{B}$ and $\mathrm{C}$ in $\mathrm{SCPI}^{+}$strains. Spot $\mathrm{B}$ was shown to be methylenomycin A by Wright \& Hopwood (I976a). Spot C, which in our hands always contained more material than spot B irrespective of which of the three species was involved, is probably structurally related to methylenomycin A and may be the compound identified in preparative chromatography and differing from methylenomycin A by 16 mass units (Wright \& Hopwood, 1976a). Spot B from S. lividans and $S$. parvulus was shown to inhibit Bucillus cereus by the method of Kirby et al. (1975). Thus the SCPI plasmid apparently confers on these two species the capacity to produce the same antibiotic as in $S$. coelicolor.

Transfer of SCPI-orange to $S$. lividans and $S$. parvulus was important to discriminate between two hypotheses on the nature of the orange pigment: (i) that it was a precursor or side product of methylenomycin synthesis, or (ii) that it was an intermediate or side product of the actinorhodin pathway caused to accumulate by interference with that pathway by a compound accumulating as a result of interruption of the methylenomycin pathway. Streptomyces parvulus does not produce actinorhodin or related pigments; S. lividans usually does not, although occasionally some colonies give rise to a pigment that is blue in alkaline conditions and may be actinorhodin (B. A. M. Rudd, personal communication). SCPI-orange was transferred to these species by crossing strain 2455 ( $S$. coelicolor SCPIorange) with streptomycin-resistant mutants of $S$. lividans or $S$. parvulus and selecting colonies resistant to methylenomycin and streptomycin on CM containing both antibiotics. All such colonies produced orange pigment on $\mathrm{CM}$. Thus this pigment is probably directly asscciated with the methylenomycin pathway rather than the actinorhodin pathway and SCPI-orange represents a unique class of mmy mutation.

Some representative mmy mutants of $\mathrm{SCPl}^{\prime}-c y s B^{+}$(R39, R40 and R48) were crossed with $S$. parvulus cysBI (strain 2297) and $\mathrm{Cys}^{+} S$. parvulus progeny were tested for antibiotic production against strain II90. None was detected; thus the phenotype of the mutants remained $\mathrm{Mmy}^{-}$in this species.

\section{Classification of mmy mutations}

Chromatography. Extracts of liquid cultures of each mutant were compared chromatographically with those of $\mathrm{SCPI}^{+}$and $\mathrm{SCP}_{1}{ }^{-}$cultures. Each mutant extract yielded the u.v.absorbing spot $\mathrm{A}$, which is probably unrelated to methylenomycin (see above). However, spots $\mathrm{B}$ and $\mathrm{C}$, characteristic of $\mathrm{SCPI}^{+}$cultures, were not seen in extracts of any of the mutants, with the exception of a very small amount of u.v.-absorbing material sometimes seen in the spot $\mathrm{C}$ position in R274. Faint u.v.-absorbing spots with other $R_{F}$ values were occasionally seen in particular mutant extracts, but their presence was not completely reproducible. 


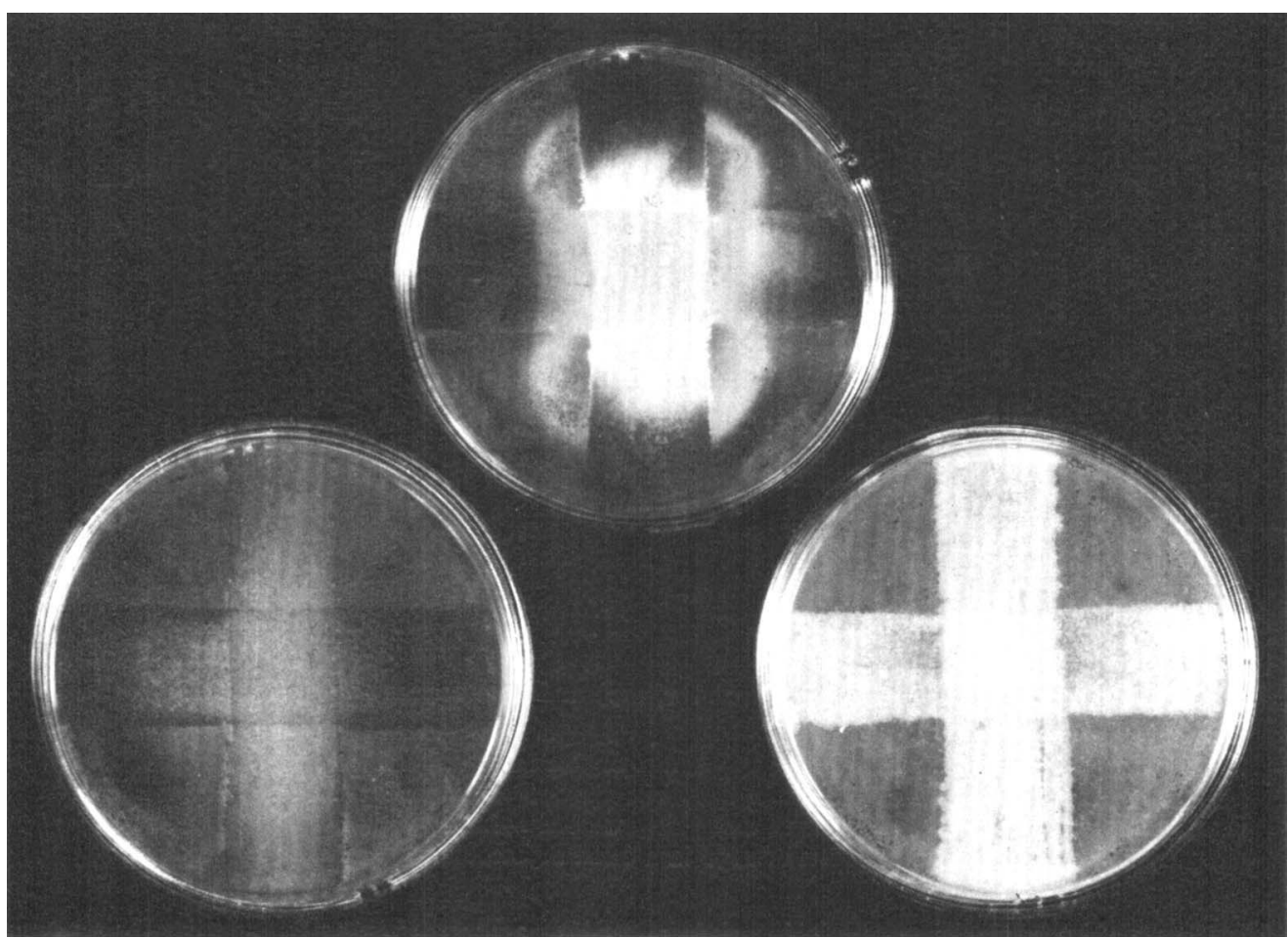

Fig. 2. Tests of antibiotic co-synthesis between pairs of mmy mutants. Each dish shows a pair of mutants, inoculated vertically and horizontally, on a background of $\mathrm{SCP}^{-}$strain I I90. Top: R39 (vertical), R284 (horizontal); antibiotic co-synthesis, with R284 acting as secretor and R39 as converter. Left : R48 (vertical), R39 (horizontal); no co-synthesis. Right: RI I (vertical), R33 (horizontal); no co-synthesis. Note that R39, R48 and R284 are pigmented; RII and R33 are non-pigmented.

Co-synthesis. Ideally, complementation tests would reveal allelism or otherwise of the mmy mutations. However, these are not yet available for SCPI-linked mutations since cohabitation of hyphae by a pair of SCPI derivatives is very limited. In initial tests for pairwise interactions between mutants, they were inoculated at right angles on plates of CM carrying the $I 190$ indicator strain, by successive replication from plates carrying a streak of each mutant separately (Fig. 2). Clear evidence of antibiotic production was seen in most pairs involving R39 and the zone of inhibition was markedly asymmetrical, extending from the area of contact of the two mutants along the R39 streak (Fig. 2, top). We were evidently observing a co-synthesis reaction (McCormick et al., 1960) with R39 acting as converter of material secreted by the other (later blocked) mutant. All the mutants, except R48, R56 and R332 but including SCPI-orange, acted as secretors to R39 in these tests. No strong and unambiguously asymmetric reactions were seen in pairs not involving R39, although a very weak reaction was sometimes seen between $\mathbf{R} 48$ and $\mathbf{R} 284$.

Erwinia carotovora is a useful specific indicator for methylenomycin since it is totally insensitive to cultures of $\mathrm{SCPI}^{-}-S$. coelicolor derivatives, being resistant to the actinorhodin antibiotic (Wright \& Hopwood, I $976 a, b$ ). Tests of co-synthesis between each pair of mmy mutants were therefore repeated using the method of Delić, Pigac \& Sermonti (1969) and E. carotovora as indicator (Fig. 3). This test might have been more sensitive than tests with strain I I90, but there was complete agreement between the results of the two methods. 


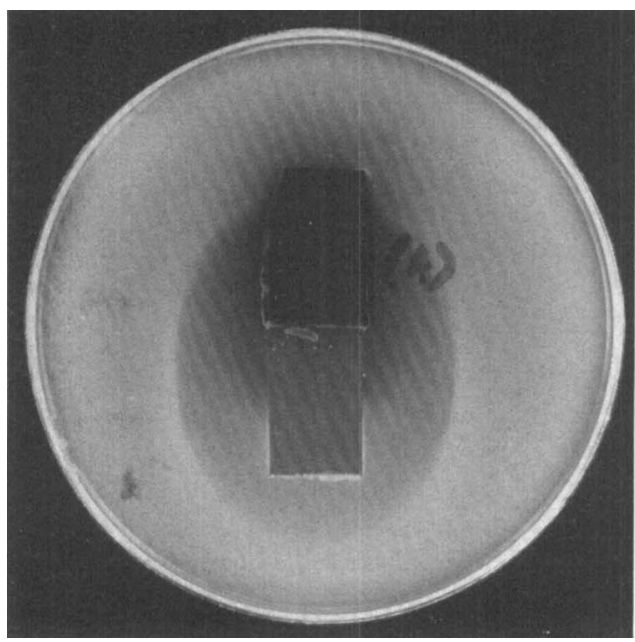

Fig. 3

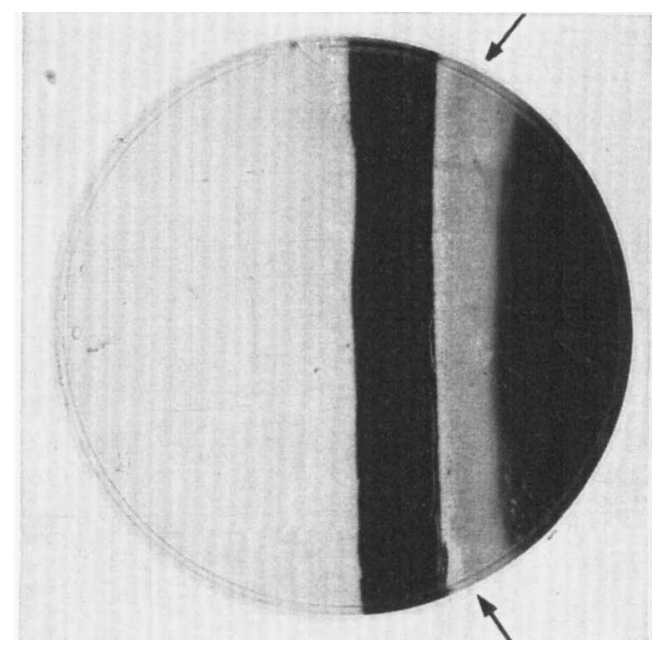

Fig. 4

Fig. 3. Antibiotic co-synthesis by R40 (secretor, top) and R39 (converter, bottom) tested against Erwinia carotovora.

Fig. 4. Antibiotic co-synthesis between R39 and R40. The left-hand half of the dish is blank agar into which antibiotic precursor from $\mathrm{R} 4 \mathrm{O}$ had been allowed to diffuse from a culture in the righthand half of the dish. This was later replaced by a narrow strip of an R39 culture and a segment of agar carrying strain II90. Note inhibition of 1190 in a band adjacent to R39 (arrows).

To prove that a positive result involving strain R39 was due to an extracellular (cosynthetic) reaction rather than to intracellular complementation, a putative secretor mutant (R40) was inoculated on half the surface of a CM plate and after 3 days' incubation this section was completely removed. A $2 \mathrm{~cm}$ wide strip of a 3-day-old R39 culture was placed beside the remaining uninoculated agar, and the rest of the dish was filled by a segment of CM carrying a I-day-old lawn of strain I I90. Inhibition of this test lawn on further incubation confirmed true co-synthesis (Fig. 4). Controls consisted of plates with the secretor and converter reversed.

To confirm that the inhibition produced in co-synthetic reactions was due to methylenomycin production, extracts of mixed shake flask cultures of R39 with R33, R40, R48 or R274 were analysed chromatographically. The combinations shown earlier to co-synthesize on agar (R39 with R33, R40 or R274) produced spots A, B and C, while the R39 plus R48 combination, which failed to co-synthesize on agar, revealed spot $\mathrm{A}$ only.

In tests in which strain I04 (SCPI ${ }^{+}$), each mmy mutant and I I90 were juxtaposed (Fig. 5), it was found that $\mathrm{R} 39$, but no other mutant, was able to convert material secreted by the $\mathrm{SCPI}^{+}$culture to antibiotic.

Pigmentation. The mutants differed reproducibly in their pigmentation on CM. On this medium, a typical $\mathrm{SCPI}^{-}$strain, such as $\mathrm{II}_{190}$, produces large quantities of reddish-purple pigment, the main component of which is the $\mathrm{pH}$ indicator antibiotic actinorhodin (Wright \& Hopwood, 1976b) although other pigments are also present (Z. Hoštalek, personal communication; B. A. M. Rudd, unpublished results). Pigmentation of strain I04, isogenic with I I90 except for the presence of SCPI, was considerably delayed on CM; it was strawcoloured when 1 I90 was deeply pigmented. On supplemented MM, on which methylenomycin is barely produced, both strains were strongly pigmented. Thus it is likely that inhibition of pigmentation of $\mathrm{SCPI}^{+}$cultures on $\mathrm{CM}$ is related to the production of methylenomycin 


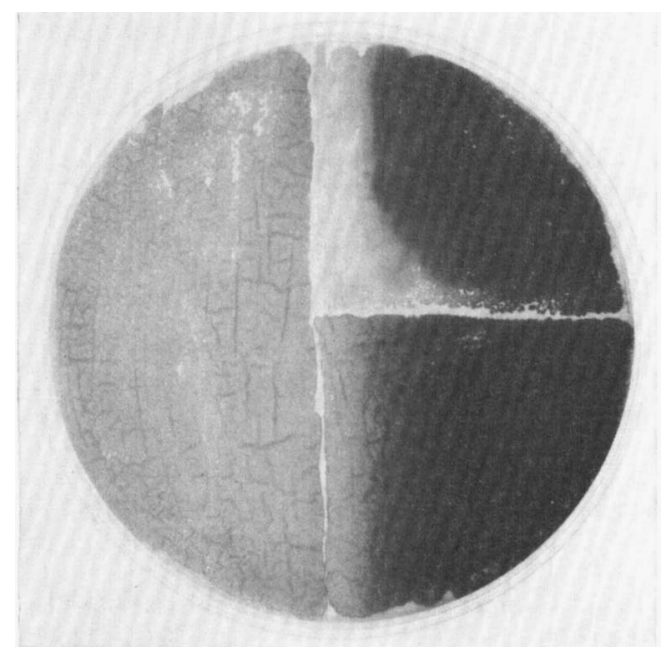

Fig. 5. Co-synthesis of antibiotic by $m m y^{+}$strain 104 (left-hand half of dish) and R39 (bottom right-hand quadrant) detected by inhibition of strain 190 (top right-hand quadrant). Note inhibition of 1190 by 104, and further inhibition due to antibiotic synthesized by R39 in proximity to I04.

or a precursor of it. It was therefore significant that the mmy mutants fell clearly into two classes on $\mathrm{CM}$; some were as deeply pigmented as $\mathrm{SCPI}^{-}$strains of the same age, while others were as pale as $\mathrm{SCPI}^{+}$strains (Fig. 2; Table 2). It is possible that pigmentation may be inhibited by a precursor of methylenomycin $A$ and that the pale mutants represent later blocks in methylenomycin synthesis than the pigmented mutants.

The mutant R274 was difficult to classify; while often causing appreciable inhibition of pigment production by strain I I90, it caused little, if any, inhibition of its growth; moreover it failed to inhibit $E$. carotovora, and only traces of spot $\mathrm{C}$ could be seen in chromatographic analysis (see above). It is possible that R274 accumulated a material, different from methylenomycin $\mathbf{A}$, which inhibited pigment production; however, a slight leakiness of the mutation, at least at temperatures slightly below $30^{\circ} \mathrm{C}$, might have explained the results.

Grouping of mmy mutations into phenotypic classes. Two of the SCPI-linked mutations conferred unique phenotypes on their host strain and each therefore defines a phenotypic class: R39 was the only mutant unambiguously to act as converter in co-synthesis; while SCPI-orange caused the production of an orange pigment. Two mutants (R56 and R332) failed to co-synthesize with any other mutant and therefore define a third class, which also contains R48 if its weak co-synthetic reaction with R284 is disregarded. The remaining large group of mutants that co-synthesized as secretors with R39 is sub-divisible into two further classes on the basis of pigmentation. The distribution of the mutations into five classes on these criteria is shown in Table 4 . It should be noted that this represents a minimum subdivision of the mutations; further classes would result if the weak co-synthetic reaction involving R48 and R284 were taken into account; moreover, R274, with its dubious and possibly temperature-sensitive phenotype, has been disregarded; it might possibly represent an additional class. The only mutations in the same class which might be clonal are R284 with R289 and R3I6 with R33I (see Table 2). 
Table 4. Classification of mmy mutants

\begin{tabular}{|c|c|c|c|}
\hline Class & Characteristics & $\begin{array}{l}\text { No. in } \\
\text { class }\end{array}$ & Members \\
\hline R39 & $\begin{array}{l}\text { Pigmented; co-synthesizes (as converter) with } \\
\text { R40, RII and SCPI-orange }\end{array}$ & $\mathbf{I}$ & R39 \\
\hline R40 & $\begin{array}{l}\text { Pigmented; co-synthesizes (as secretor) with } \\
\text { R39 }\end{array}$ & 7 & $\begin{array}{l}\text { R27, R40, R53, R284, } \\
\text { R289, R3I6, R33I }\end{array}$ \\
\hline R I I & $\begin{array}{l}\text { Non-pigmented; co-synthesizes (as secretor) } \\
\text { with R39 }\end{array}$ & 3 & $\mathrm{RII}, \mathrm{R} 33, \mathrm{R} 333$ \\
\hline SCPI-orange & $\begin{array}{l}\text { Orange-pigmented; co-synthesizes (as secretor) } \\
\text { with R39 }\end{array}$ & $\mathbf{I}$ & SCPI-orange \\
\hline R56 & Pigmented; no co-synthesis & 3 & $\begin{array}{l}\mathrm{R} 56, \mathrm{R} 332, \text { and } \\
\text { possibly R48 }\end{array}$ \\
\hline
\end{tabular}

Table 5. Recombination tests between pairs of mmy mutants of $\mathrm{SCPr}^{\prime}-c y s B^{+}$in the R40 group

Frequencies are those of $m m y^{+}$colonies amongst $\mathrm{Cys}^{+}$recombinants of triparental crosses between two mmy mutants of strain $1984\left(\mathrm{SCPI}^{\prime}-c y s B^{+}\right)$and strain 1953 . Percentage frequencies are in parentheses.

\begin{tabular}{|c|c|c|c|c|c|c|}
\hline 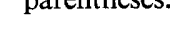 & R40 & R53 & R284 & R289 & R3I 6 & R33 I \\
\hline R40 & & $\begin{array}{c}0 / 3339 \\
(<0.03)\end{array}$ & $\begin{array}{c}7 / 6450 \\
(0 \cdot 1)\end{array}$ & $\begin{array}{c}2 / 4500 \\
(0.05)\end{array}$ & $\begin{array}{c}2 / 5800 \\
(0.04)\end{array}$ & $\begin{array}{c}0 / 2712 \\
(<0.04)\end{array}$ \\
\hline R53 & & & $\begin{array}{c}0 / 4550 \\
(<0.02)\end{array}$ & $\begin{array}{c}0 / 3760 \\
(<0.03)\end{array}$ & $\begin{array}{c}0 / 3780 \\
(<0.03)\end{array}$ & $\begin{array}{c}0 / 5100 \\
(<0.02)\end{array}$ \\
\hline R284 & & & & $\begin{array}{c}0 / 6350 \\
(<0.02)\end{array}$ & $\begin{array}{l}I / 5320 \\
(0.02)\end{array}$ & $\begin{array}{c}0 / 4010 \\
(<0.03)\end{array}$ \\
\hline R289 & & & & & $\begin{array}{c}2 / 4600 \\
(0.05)\end{array}$ & $\begin{array}{c}0 / 5400 \\
(<0.02)\end{array}$ \\
\hline R3I 6 & & & & & & $\begin{array}{c}0 / 4950 \\
(<0.02)\end{array}$ \\
\hline $\begin{array}{l}\text { Reversion } \\
\text { frequency }\end{array}$ & $\begin{array}{l}0 / 3960 \\
(<0.03)\end{array}$ & $\begin{array}{c}0 / 5390 \\
(<0.02)\end{array}$ & $\begin{array}{c}0 / 4850 \\
(<0.02)\end{array}$ & $\begin{array}{c}0 / 5710 \\
(<0.02)\end{array}$ & $\begin{array}{c}0 / 3250 \\
(<0.03)\end{array}$ & $\begin{array}{c}0 / 3400 \\
(<0.03)\end{array}$ \\
\hline
\end{tabular}

\section{Reversion of mmy mutants}

Reversion tests were done on some of the mmy mutants, $\mathrm{Mmy}^{+}$colonies being sought among samples of 3000 to 8000 colonies. No spontaneous revertants were found, but some of the mutants (R39, R48, R53, R316) reverted after mutagenesis by NTG or MOP at frequencies in the order of 0.05 to $0.1 \%$. It was not feasible to examine larger populations of colonies, and negative results obtained with R40, R284 and R289 were therefore not evidence of non-revertibility. For those mutants that reverted, three revertants were tested and all showed plasmid linkage of the $\mathrm{Mmy}^{+}$phenotype.

\section{Recombination of mmy mutants}

Recombinants arose from crosses between pairs of mutants in different phenotypic classes (Table 4) with the following frequencies: R39 $\times \mathrm{R} 48,7 / \mathrm{I} 860(0.4 \%) ; \mathrm{R} 40 \times \mathrm{R} 48$, $8 / 474(2 \%)$; $48 \times R 53,8 / 635(\mathrm{I} \%)$. In a further series of crosses between all possible pairs of a sample of mutants in the same class, recombination frequencies in the range 0.02 to $0.1 \%$ were observed in some crosses, but large enough samples of progeny could not be examined to make the negative results significant (Table 5). Although no individual positive result was significantly above the detection limit for spontaneous revertants (Table 5), controls yielded no revertants, and it is therefore very unlikely that all the apparent recom- 
Table 6. Crosses of $\mathrm{SCPI}^{-}$with mmy mutants of an $\mathrm{NF}$ strain

The $m m y \times \mathrm{SCPI}^{-}$data are combined results from crosses of $\mathrm{RII}$ and $\mathrm{R} 33$ (hisAI uraAI strAI NF) with $\mathrm{A} 700$ ( $p r o A I \arg A I$ cys DI $8 \mathrm{SCPI}^{-}$); the $m m y^{+} \times \mathrm{SCPI}^{-}$cross was $\mathrm{A} 303$ (hisAI uraAI strAI NF) $\times$ A700

\begin{tabular}{|c|c|c|c|c|c|c|}
\hline \multirow{2}{*}{ Genotype } & & \multicolumn{2}{|c|}{ Number } & \multicolumn{2}{|c|}{$\begin{array}{l}\text { Percentage of } \\
\text { total progeny }\end{array}$} & \multirow[b]{3}{*}{ Description } \\
\hline & & \multirow{2}{*}{$\begin{array}{c}m m y(\mathrm{NF}) \\
\times \\
\mathrm{SCPI}^{-}\end{array}$} & \multirow{2}{*}{$\begin{array}{c}m m y^{+}(\mathrm{NF}) \\
\times \\
\mathrm{SCPI}^{-}\end{array}$} & \multirow{2}{*}{$\begin{array}{l}m m y(\mathrm{NF}) \\
\times \\
\mathrm{SCPI}^{-}\end{array}$} & \multirow{2}{*}{$\begin{array}{c}m m y^{+}(\mathrm{NF}) \\
\times \\
\mathrm{SCPI}^{-}\end{array}$} & \\
\hline Chromosomal markers & Plasmid & & & & & \\
\hline his ura str & $\mathbf{N F}$ & 125 & 19 & 32 & 10 & Donor parental \\
\hline pro arg cys & $\mathrm{SCPI}^{-}$ & 17 & 0 & 4 & 0 & Recipient parental \\
\hline pro arg cys & NF & 136 & $8 \mathrm{I}$ & & & \\
\hline pro arg cys ura & NF & 67 & 77 & & & \\
\hline $\arg$ cys & NF & I 8 & 6 & & & \\
\hline arg cys ura & NF & 17 & 6 & & & \\
\hline his arg cys & NF & I & $\mathbf{I}$ & & & \\
\hline his arg cys ura & NF & I & I & & & \\
\hline his cys & $\mathrm{NF}$ & I & I & & & \\
\hline his cys ura & NF & I & 0 & 64 & 90 & Recombinants \\
\hline pro arg cys ura str & NF & I & 0 & & & \\
\hline pro arg ura str & NF & $\mathbf{I}$ & 0 & & & \\
\hline pro arg cys str & NF & I & 0 & & & \\
\hline his pro cys ura & $\mathbf{N F}$ & 0 & I & & & \\
\hline pro arg & NF & 0 & I & & & \\
\hline cys ura & NF & $\mathbf{I}$ & 0 & & & \\
\hline pro cys & NF & I & 0 & & & \\
\hline
\end{tabular}

bination frequencies in Table 5 are spurious, if indeed any of them are. In any case, it is noteworthy that the apparent within-class recombination frequencies $(0.02$ to $0.1 \%)$ were an order of magnitude below the between-class values of 0.4 to $2 \%$.

Ultra-fertility in crosses of $\mathrm{SCPI}^{-}$with mmy mutants of an NF strain

Crosses of NF and SCPI- (UF) strains have been described as 'ultra-fertile' (Hopwood et al., 1969) since they yield very low proportions of either parental genotype. The explanation of the almost total absence of the donor $(\mathrm{NF})$ parental type from the progeny is a mystery. However, the finding of inhibition of $\mathrm{SCPI}^{-}$strains by those carrying SCPI, including NF, provided a possible explanation for the absence of the $\mathrm{SCPI}^{-}$genotype (Vivian, I97I; Hopwood et al., 1973).

To test this idea we analysed crosses of the NF mmy mutants (RI I and R33) with an SCPIstrain (A700). All progeny were classified in respect of chromosomal markers and tested for antibiotic production against strain I I90. The progeny from the $m m y \times \mathrm{SCP}^{-}$crosses were tested for methylenomycin resistance by replica-plating to plates containing methylenomycin A. Such crosses gave results (Table 6) similar to those of the control NF $\left(m m y^{+}\right) \times \mathrm{SCPI}^{-}$ cross. There was, however, a larger proportion of the NF parental type amongst the progeny (over $30 \%$ compared with $10 \%$ in the control, itself a rather high value for an $\mathrm{NF} \times \mathrm{SCPI}^{-}$ cross) and a small proportion ( $4 \%$ ) of the $\mathrm{SCPI}^{-}$recipient genotype.

None of the progeny of the crosses involving RII or R33 was Mmy+. Although not providing complete proof of SCPI-linkage, these results strongly suggest it. If the $m m y$ mutations in RI I or R33 were in chromosomal genes, these would have had to be very close to the site of plasmid integration. 


\section{DISCUSSION}

There is evidence for plasmid involvement in the synthesis of several streptomycete antibiotics (Akagawa, Okanishi \& Umezawa, 1975; Boronin, Borisoglebskaya \& Sadovnikova, 1974; Kähler \& Noack, I974; Okanishi, Ohta \& Umezawa, 1970). However, uniquely for methylenomycin synthesis by $S$. coelicolor A3(2), there is now extensive genetical characterization of the plasmid concerned and substantial evidence that the plasmid carries the structural genes for the biosynthetic pathway of the antibiotic. This evidence is described in the present paper and is of two kinds. Firstly, when SCPI was transferred to two other species that do not normally produce the antibiotic, $S$. lividans and $S$. parvulus, material that was biologically and chromatographically identical with methylenomycin A was synthesized. If SCPI acted only in a regulatory role, one would have to postulate 'silent' pathway genes in these two species. Secondly, all 16 of the mmy mutations so far known are SCPI-linked. Chromosomal mutations abolishing methylenomycin synthesis have been isolated in other studies, but these are the bald mutations that interfere with the development of aerial mycelium (Chater \& Merrick, 1976; Merrick, 1976); they also lead to lack of actinorhodin. Wide pleiotropic effects undoubtedly result from these mutations and it is most unlikely that the genes defined by them are primarily concerned with methylenomycin.

Classification of the mmy mutations is complicated by the possibility that some may not be point mutations. One of the mutants, SCPI-orange, probably owes its increased capacity to donate chromosomal markers to a chromosomal insertion and it is also suggestive that one of the SCPI'-argA, uraB strains (1937) described by Hopwood \& Wright (I976a) had an $\mathrm{Mmy}^{-}$phenotype; it was too unstable to include in the present study. Furthermore, several of the mutants selected on the basis of the $\mathrm{Mmy}^{-}$phenotype were altered in other ways: stability, transfer proficiency, 'entry disadvantage' and methylenomycin sensitivity. We cannot yet say whether these resulted from single pleiotropic mutations or from more complex genetic changes. However, reversions of mutations in three of the five phenotypic classes (R39, R40 and R56) were easily found, suggesting that they, at least, were not multi-site events. Since two of the classes have only one member, other classes will presumably be revealed by a larger sample of mutations, especially if a reliable method of studying complementation between the mutations becomes available

It is premature to speculate at length on the sequence of pathway interruptions represented by the mutations, until biochemical studies can be used to define the biosynthetic steps involved. Since co-synthesis was rare amongst the I6 mutations, only one of which acted as a converter, this criterion was much less useful than in the case of the tetracyclines (Delić et al., I969; Boronin \& Mindlin, 197I) or platenomycins (Furumai \& Suzuki, 1975). Possibly many of the intermediates of methylenomycin A biosynthesis are highly labile, unable to cross permeability barriers, or are enzyme-bound.

The mmy mutations are relevant to the mechanism of ultra-fertility of $\mathrm{NF} \times \mathrm{SCPI}^{-}$crosses and also to the role, if any, of the plasmid-determined antibiotic in the retention of autonomous SCPI and its derivatives by the mycelium. The finding that mmy mutants of NF were highly fertile in crosses with $\mathrm{SCPI}^{-}$eliminates the simple possibility that the almost total absence of $\mathrm{SCPI}^{-}$progeny in a normal $\mathrm{NF} \times \mathrm{SCPI}^{-}$cross is due to selection against them by methylenomycin produced during growth of the cross. Similarly, it could have been argued that the wild-type autonomous plasmid is potentially lost from a significant proportion of the hyphal units in a culture but that these are selected against by the antibiotic. However, the finding that many of the mmy mutants were lost no more often than the parent $m m y^{+}$plasmid argues against this idea. 
Kirby (1974) described recombination between SCPI derivatives, selection being for transfer proficiency when the parent plasmids were defective in transfer. In the present study, recombination was detected by the production of $m m y^{+}$progeny in crosses between pairs of mmy mutations. Crosses between mutations of the same phenotypic class yielded recombinants at frequencies that could not be unambiguously distinguished from those of reverse mutation, although reversion was very unlikely to have explained the results. However, in crosses between phenotypically different mutations, significant levels of recombination certainly occurred. Whether recombination can be used as a means of mapping plasmid-borne genes remains to be seen.

One of us (R.K.) is grateful to the Trustees of the John Innes Charity for a postgraduate studentship.

\section{REFERENCES}

Akagawa, H., Okanishi, M. \& Umezawa, H. (1975). A plasmid involved in chloramphenicol production in Streptomyces venezuelae: evidence from genetic mapping. Journal of General Microbiology 90, 336-346.

Boronin, A. M. \& Mindlin, S. Z. (197I). Genetic analysis of Actinomyces rimosus mutants with impaired synthesis of antibiotic. Genetika 7, I25-I 31 (in Russian).

Boronin, A. M., Borisoglebskaya, A. N. \& Sadovnikova, L. G. (I974). Oxytetracycline-sensitive mutants of Streptomyces rimosus, the producer of oxytetracycline.'Abstracts of the Second International Symposium on the Genetics of Industrial Microorganisms, p. 103. London and New York: Adacemic Press.

ChATER, K. F. \& MerRick, M. J. (I976). Approaches to the study of differentiation in Streptomyces coelicolor A3(2). In Second International Symposium on the Genetics of Industrial Microorganisms, pp. 583593. Edited by K. D. Macdonald. London and New York: Academic Press.

Delić, V., Hopwood, D. A. \& FrIEND, E. J. (1970). Mutagenesis by $N$-methyl- $N$ '-nitro- $N$-nitrosoguanidine (NTG) in Streptomyces coelicolor. Mutation Research 9, 167-182.

Delić, V., Pigac, J. \& Sermonti, G. (I969). Detection and study of cosynthesis of tetracycline antibiotics by an agar method. Journal of General Microbiology 55, 103-108.

Furumai, T. \& SuzukI, M. (1975). Studies on the biosynthesis of basic 16-membered macrolide antibiotics, platenomycins. I. Selection of and cosynthesis by non-platenomycin-producing mutants. Journal of Antibiotics (Japan) 28, 770-774.

Haneishi, T., Kitahara, N., Takiguchi, Y., Arai, M. \& Sugawara, S. (1974). New antibiotics, methylenomycins A and B. I. Producing organism, fermentation and isolation, biological activities and physical and chemical properties. Journal of Antibiotics (Japan) 27, 386-392.

HAROLD, R. J. \& Hopwood, D. A. (1970). Ultraviolet-sensitive mutants of Streptomyces coelicolor. I. Phenotypic characterisation. Mutation Research Io, 427-438.

Hopwood, D. A. (1967). Genetic analysis and genome structure in Streptomyces coelicolor. Bacteriological Reviews 3I, 373-403.

Hopwood, D. A. \& WRIGHT, H. M. (1973a). Transfer of a plasmid between streptomyces species. Journal of General Microbiology 77, 187-195.

Hopwood, D. A. \& WRIGHT, H. M. (I973 $b$ ). A plasmid of Streptomyces coelicolor carrying a chromosomal locus and its inter-specific transfer. Journal of General Microbiology 79, 331-342.

HopwOOD, D. A. \& WRIGHT, H. M. (1976a). Interactions of the plasmid SCPI with the chromosome of Streptomyces coelicolor A3(2). In Second International Symposium on the Genetics of Industrial Microorganisms, pp. 607-619. Edited by K. D. Macdonald. London and New York: Academic Press.

Hopwood, D. A. \& WRIGHT, H. M. (1976b). Genetic studies on SCPI-prime strains of Streptomyces coelicolor A3(2). Journal of General Microbiology 95, $107-120$.

Hopwood, D. A., Harold, R. J., Vivian, A. \& Ferguson, H. M. (1969). A new kind of fertility variant in Streptomyces coelicolor. Genetics 62, 46I -477 .

Hopwood, D. A., Chater, K. F., Dowding, J. E. \& Vivian, A. (I973). Advances in Streptomyces coelicolor genetics. Bacteriological Reviews 37, 37I-405.

KÄHLER, R. \& NOACK, D. (1974). Action of acridine orange and ethidium bromide on growth and antibiotic activity of Streptomyces hygroscopicus JA6599. Zeitschrift für allgemeine Mikrobiologie 14, 529-533.

KIRBY, R. (1974). Mutants of the SCPI plasmid of Streptomyces coelicolor A3(2). Abstracts of the Second International Symposium on the Genetics of Industrial Microorganisms, p. IOo. London and New York: Academic Press.

KIRBY, R. (1976). Genetic studies on Streptomyces coelicolor Plasmid One. Ph.D. thesis, University of East Anglia, Norwich.

KIRBY, R., Wright, L. F. \& Hopwood, D. A. (1975). Plasmid-determined antibiotic synthesis and resistance in Streptomyces coelicolor. Nature, London 254, 265-267. 
Lomovskaya, N. D., Mkrtumian, N. M., Gostimskaya, N. L. \& Danilenko, V. N. (1972). Characterization of temperate actinophage $\phi \mathrm{C}_{3} \mathrm{I}$ isolated from Streptomyces coelicolor A3(2). Journal of Virology 9 , $258-262$.

McCormick, J. R. D., Hirsch, U., Sjolander, N. O. \& Doerschuk, A. P. (1960). Cosynthesis of tetracyclines by pairs of Streptomyces aureofaciens mutants. Journal of the American Chemical Society 82, 5006-5007.

MerRICK, M. J. (1976). A morphological and genetic mapping study of bald colony mutants of Streptomyces coelicolor. Journal of General Microbiology 96, 299-315.

OKanishi, M., OHTA, T. \& UMeZAWA, H. (1970). Possible control of formation of aerial mycelium and antibiotic production in Streptomyces by episomic factors. Journal of Antibiotics (Japan) 23, 45-47.

Townsend, M. E., WRIGHT, H. M. \& Hopwood, D. A. (197I). Efficient mutagenesis by near ultraviolet light in the presence of 8-methoxypsoralen in streptomyces. Journal of Applied Microbiology 34, 799801 .

VIvian, A. (197I). Genetic control of fertility in Streptomyces coelicolor A3(2): plasmid involvement in the interconversion of UF and IF strains. Journal of General Microbiology 69, 353-364.

VIvian, A. \& Hopwood, D. A. (1970). Genetic control of fertility in Streptomyces coelicolor: the IF fertility type. Journal of General Microbiology 64, IOI-1 17.

Vivian, A. \& Hopwood, D. A. (1973). Genetic control of fertility in Streptomyces coelicolor A3(2): new kinds of donor strains. Journal of General Microbiology 76, 147-162.

WRIGHT, L. F. \& HoPwOOD, D. A. (1976a). Identification of the antibiotic determined by the SCPI plasmid of Streptomyces coelicolor A3(2). Journal of General Microbiology 95, 96-106.

WRIGHT, L. F. \& Hopwood, D. A. (I976b). Actinorhodin is a chromosomally-determined antibiotic in Streptomyces coelicolor A3(2). Journal of General Microbiology 96, 289-297. 